International Journal of Engineering \& Technology, 7 (2.21) (2018) 53-57
International Journal of Engineering \& Technology
SPC
Website: www.sciencepubco.com/index.php/IJET
Research paper

\title{
Stochastic voltage stability margin in unbalance feeder with fuzzy based distributed generation placement
}

\author{
Jagdish Prasad Sharma ${ }^{1 *}$, H. Ravishankar Kamath ${ }^{2}$ \\ ${ }^{1}$ Department of Electrical Engineering, JK Lakshmipat University, Jaipur, India. \\ ${ }^{2}$ Department of Instrumentation \& Control Engineering, MIT, Manipal, India. \\ *Corresponding author E-mail:jpsharma.jklu@gmail.com
}

\begin{abstract}
In this paper, the impact of distributed generation (DG) integration on worst stochastic voltage stability margin is investigated for a modified IEEE 37 node test system. This unbalance test system has voltage sensitive load model for industrial, commercial and residential consumers and load flow computed in MATLAB environment with 15 minutes metering time interval for a whole day. DG integration is based on fuzzy expert system and integrated between 35 to 73 period of metering time interval. The stochastic voltage stability margin for all phase are evaluated under three different DG operational scenarios and compared with results obtained in the base case. The cause and consequence of unbalance phenomena is also broadly discussed in detail.
\end{abstract}

Keywords: Voltage stability margin, stochastic feeder performance, unbalances phenomenon, distributed generation, IEEE 37 Feeder.

\section{Introduction}

In a deregulated environment, voltage stability margin has become a serious concern for secure and stable operation of an integrated distribution system. An increased penetration level of distributed generation has restricted renovation and augmentation works of an existing system, which raised a great challenge for both utilities and researchers. The voltage instability for integrated unbalance distribution feeder has serious issues regarding load flow convergence, voltage dependent load models, feeder topology and mal functioning of controlling devices.

The voltage stability analysis for a radial balanced and unbalanced distribution systems are reported by many authors. A voltage stability limit is demonstrated for a distribution system by M.H.Haqu[1]. A reduced pi equivalent model for each branch of feeder is employed for voltage stability analysis of a distribution feeder [2].Voltage deviation and line loading margin computed using a line loading index for a distribution system [3]. To evaluate voltage stability and security at appropriate levels, two indicators are utilized for load flow study [4]. The voltage dependency characteristics and composition of load models for different category consumers such as residential, commercial and industrial possessed load flow convergence problem. For a realistic feeder, stochastic voltage stability is required to inculcate characteristics and composition of time varying load models. A Jacobin matrix for voltage security limit employed for a distribution feeder having various category consumers with voltage sensitive model [5].A daily performance of an unbalance distribution feeder is computed by stochastic performance indices [6].J.P.Sharma and H.R. Kamath proposed voltage stability margin for an unbalanced stochastic load flow [7].

A DG unit can be operated as either in PV or PQ mode. An impact study of variable DG penetration level on losses and voltage deviation has been investigated on a modified IEEE 37-node with different load models [8].S. Banerjee et al. presented a reactive loading index to predict voltage stability margin (VSM) for 33 node feeder with composite loads [9]. At specified load, maximum allowable PV penetration assessment has been done with the help of terminal count and total feeder impedance [10].

In restructured environment, distributed generation integration brought economic, environmental and technical benefits for unities and consumers. In this context, voltage stability has emerged as a serious concern for an integrated distribution system and emerged as an active area for researchers.

The performance indices referred in [5] are utilized for optimal siting and size of DG by fuzzy expert system [11].In order to improve voltage stability for grid integrated wind farm, an effective fuzzy logic approach proposed and results are compared with the conventional solutions [12]. J. Xu. et al., analyzed voltage stability for an IEEE 14-bus test system using adaptive fuzzy logic based random load distribution [13]. J. H. Angelim and C. M. Affonso has investigated the impact of location and types of DG unit on voltage stability and power losses[14].Voltage stability margin significantly affected by the type, location and penetration level of DG units. In this lieu, P. Mehta et al., has presented a voltage sensitivity index and bus participation factors to select best location and type of DG units[15].M. A. Azzouz et al., proposed fuzzy based control algorithms to coordinate voltage regulation for an integrated distribution systems using OPAL-RT real-time simulator [16].Voltage rise for a grid-connected photovoltaic (PV) systems is serious concern and can be mitigate with reactive power compensator. Qamar et al., has mitigated voltage rise at the point of common coupling (PCC) by controlling reactive power injection with the fuzzy logic controllers [17].

In this paper, worst stochastic voltage stability margin has been evaluated with ZIP load models under three different DG operational scenarios and compared with results obtained in the base case. The unbalance phenomena for a radial distribution feeder are also discussed. The unbalance load flow has been computed for 15 minutes metering time interval for a whole day. 


\section{Unbalance Phenomenon}

An inhererent unbalance nature of a distribution feeder and voltage sensitiveness of connected load has constrained the progressions for proficiency upgrades, cost diminishes, and power quality improvements. In India, most of distribution system have overhead configuration and the common characteristics of overhead lines are low reactance to resistance ratio, radial topology, lengthy feeder, and unbalance and scattered loading.

\section{Causes and effects of unbalance phenomenon}

Asymmetrical value of voltage, current and power caused by structural unbalance nature of feeder and operational strategies are as follows.

- Imbalance of feeder and single phase load concentration

- Low quality of feeder construction consumer appliances and inadequate maintenance of equipment

- Inappropriate of distribution lines and distribution transformers and underutilization of distribution transformers

- Low power factor due to irrigation load, air conditioners, industrial loads and inadequate reactive compensation

- Improper load balancing and lengthy lateral/sub lateral lines

- Diverse composition and voltage sensitive characterization of load models

Thus, an unbalance operation of a distribution feeder has resulted in below mentioned consequences.

- Higher transformer failure rate and energy loss

- Reduced equipment life cycle and mal operation of protection system

- Increased cost of supply and operational cost

- Poor quality and reliability of power supply

\section{Parameters for unbalance conditions}

The common factor for unbalance conditions for distribution feeder is as follows $[18,19]$.

- Substation reserve capacity and apparent power unbalance

- Feeder loss-to-load ratio

- Voltage unbalance and deviation

- Power factor and voltage security

- Branch over current loading

\section{Unbalance reduction measures}

Utilities have taken up below common measures to minimize unbalance in electrical distribution systems.

- Three phase load balancing and load transfer/ curtailment

- Reactive power compensation and feeder reconfiguration

- Optimal sizing transformers and upgradation of distribution line

- Conservation voltage reduction and distributed generation integration

\section{Computational work}

\section{Test system and load flow computation}

The modified IEEE 37 distribution test feeder with delta connected load buses having a mix of industrial, residential and commercial consumers and follow a typical normalized load pattern obtained as shown in Fig.1. The load model for each type of category consumers described as a mix of constant power (PQ), constant impedance (Z) and constant current (I) models. Each feeder component is modeled with $\mathrm{ABCD}$ parameters. The metering time interval for a whole day is taken as 15 minutes.Connectivity of all nodes and radial structure of feeder are subjected to load flow constraints [06].

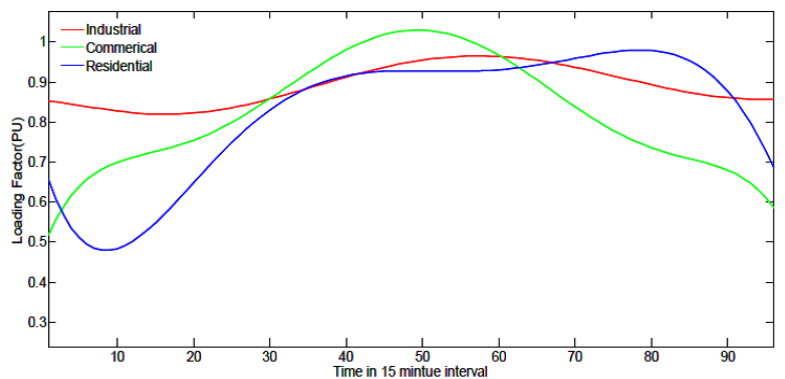

Fig. 1: Typical daily load profile for consumers

\section{Voltage stability index}

The voltage stability margin is utilized to identify the branches tend towards voltage collapse. For each series segment of a feeder an equivalent two $\pi$ bus model as mentioned in Fig. 2 .

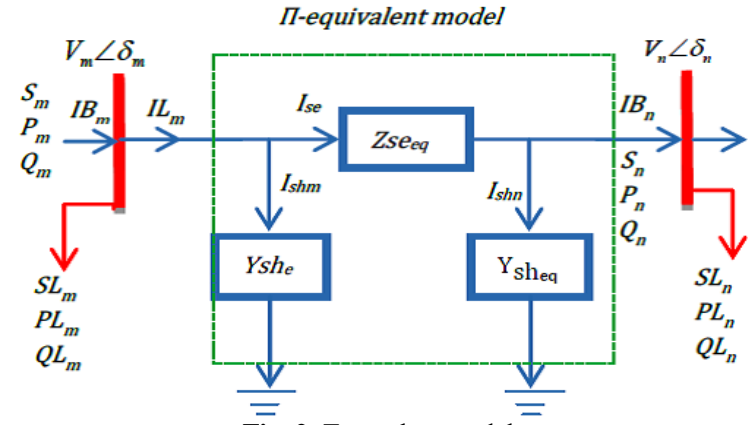

Fig. 2: Two $\pi$ bus model

For a voltage stability margin, a Jacobian matrix $\Delta[\mathrm{J}]$ is computed for each branch using Eq. (1).The branch with minimal of $\Delta[\mathrm{J}]$ is called weakest branches and should be reinforced with the support of reactive power compensation. At critical point $\Delta[\mathrm{J}]$ have zero value [07].

$\Delta J=-\left|V_{n}\right|\left|V_{m}\right|^{2}+2\left|A_{e q}\right|\left|V_{m}\right|\left|V_{n}\right|^{2} \cos \left(\delta_{m}-\propto-\delta_{n}\right)$

\section{Distributed generation}

The power electronics interface operation is regulated by coupling point variable in terms of voltage, active and reactive power injection. Thus distributed generation (DG) is designated as PQ and PV models. A constant power (PQ) DG unit operated as negative, constant power factor and variable reactive power mode. This model is commonly adopted by electric utilities [18].To keep constant power factor reactive power $\mathrm{Q}_{\mathrm{dg}}$ computed as per below equation for each iteration of load flow[20].

$\mathrm{Q}_{\mathrm{dg}}=\mathrm{P}_{\mathrm{dg}} \tan \left(\cos ^{-1}\left(\mathrm{P}_{\mathrm{dg}}\right)\right)(2)$

The PV model delivered a constant real power at fixed voltage at point of coupling and required variable reactive power to maintain fixed voltage. An appropriate procedure is needed to cater PV model for each iteration of load flow computational work. M. Tafreshi, et al., proposed a procedure to handle both PV and PQ DG unit [21]. In this paper, for PV DG unit handling, an efficient load flow algorithm is developed by incorporation of some additional process as followed. After backward load flow computation, difference in a calculated and specified voltage at PV node is computed using equation (3).In case of violation of equation (3), reactive power injection by DG units at PCC node is computed by using equation (4), (5) and (6) under different power factor.

$\left|\mathrm{VPV}_{\mathrm{abc}}\right|_{\text {itr }}-\left|\mathrm{VPV}_{\mathrm{abc}}\right|_{\text {specified }} \leq 1 e^{-5}(3)$

$\operatorname{imag}\left[\left(I P V_{\mathrm{abc}}\right)_{\mathrm{itr}}\right]=\operatorname{imag}\left[\left(\mathrm{IPV}_{\mathrm{abc}}\right)_{\mathrm{itr}-1}\right]+\operatorname{imag}\left[\left(\mathrm{IPV}_{\mathrm{abc}}\right)_{\mathrm{itr}}-\left(\mathrm{IPV}_{\mathrm{abc}}\right)_{\mathrm{itr}-1}\right]$ (4)

$\operatorname{real}\left[\left(\mathrm{IPV}_{\mathrm{abc}}\right)_{i t r}\right]=-i m a g\left[\left(\mathrm{IPV}_{\mathrm{abc}}\right)_{i t r}\right] *\left(\frac{\left.\text { imag }_{\mathrm{VPV}} \mathrm{abc}\right)_{i t r}}{\text { real }\left(\mathrm{VPV}_{\mathrm{abc}}\right)_{i t r}}\right)(5)$

$\left(\mathrm{QPV}_{\mathrm{abc}}\right)_{i t r}=\left(\mathrm{QPV}_{\mathrm{abc}}\right)_{i t r-1}+\operatorname{imag}\left[\left(\mathrm{IPV}_{\mathrm{abc}}\right)_{i t r}-\left(\mathrm{IPV}_{\mathrm{abc}}\right)_{i t r-1}\right]+$ 
$\left(\frac{a b s\left(\mathrm{VPV}_{\mathrm{abc}}\right)_{i t r}{ }^{2}}{\text { real }\left(\mathrm{VPV}_{\mathrm{abc}}\right)_{i t r}}\right)$

For medium voltage network, BDEW has recommended a guideline to keep power factor 0.95 lead or lag at point of coupling [22].The stochastic behaviour of DG integrated distribution feeder is a challenging aspect for operations and planning point of view. In this paper a fuzzy expert system as depicted in figure 3 is utilized for optimum location and sizing of single DG unit, which have capacity of DG is $440 \mathrm{KW}$ per phase and operated between 35 to 73 period of metering time interval [11]. It was observed that substation transformer got overloaded during 35 to 71 metering time interval and favorable to solar photovoltaic integration [6].In this expert system, mamdani fuzzy model is used for DG sizing, whereas sugenon fuzzy model utilized for finding location.

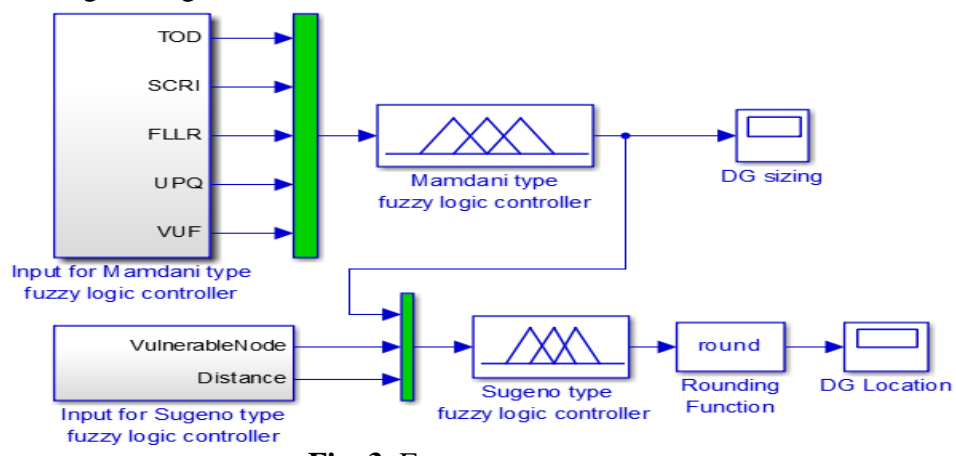

Fig. 3: Fuzzy expert system

The mamdani fuzzy model employed time of day (TOD), "substation reserve capacity (SRCI), feeder power loss to load ratio (FLLR), voltage unbalance factor (VUF) and unbalance apparent power (UPQ) indices", whereas sugenon fuzzy model utilized top 15 vulnerable nodes and their distance from substation node. These top 15 vulnerable nodes determined by survivability index (SI), a

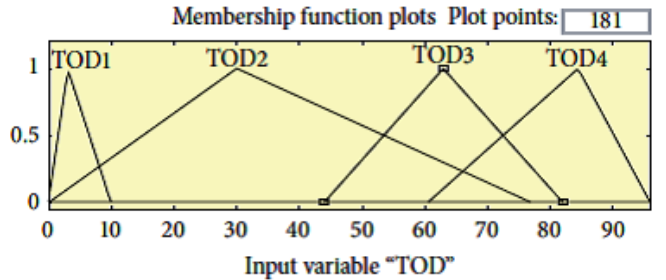

Fig. 4: Memberships function of TOD Membership function plots Plot points: 181

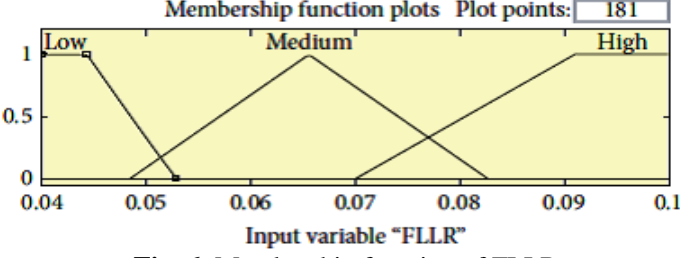

Fig. 6: Membership function of FLLR Membership function plots Plot points: 181

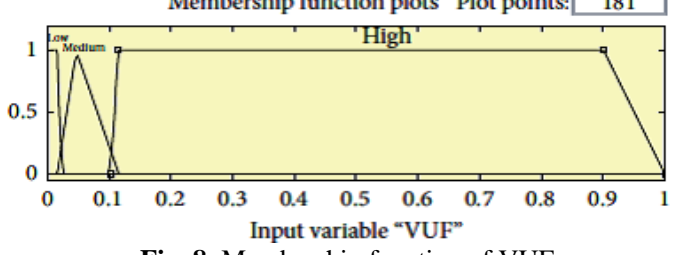

Fig. 8: Membership function of VUF

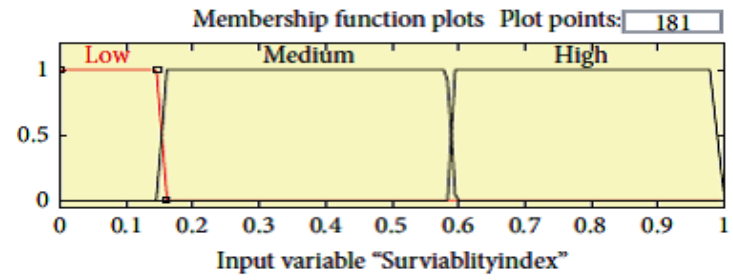

Fig. 10: Membership function of survivability index Membership function plots plot Points: 181

\begin{tabular}{|ll|}
\hline 775 & 741 \\
709 & 732 \\
708 & 731 \\
733 & 710 \\
734 & 735 \\
737 & 736 \\
738 & 740 \\
711 & \\
\hline
\end{tabular}

Output variable "DGNodeSelection"

Fig. 12: Membership functions of DG location function of voltage stability margin (VSI) and voltage deviation index (VDI)[11].The membership functions associated each crisp input/output variable and fuzzy rules shown for both fuzzy model are shown in figure 4 to 15

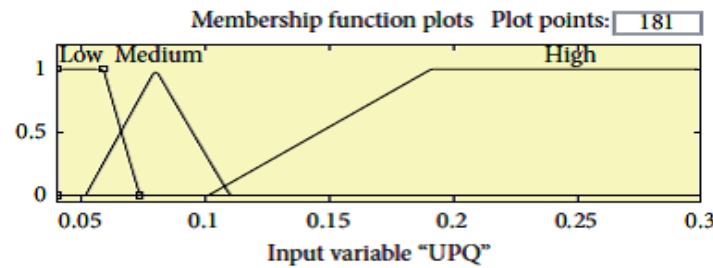

Fig. 5: Membership function of UPQ Membership function plots Plot points: 181

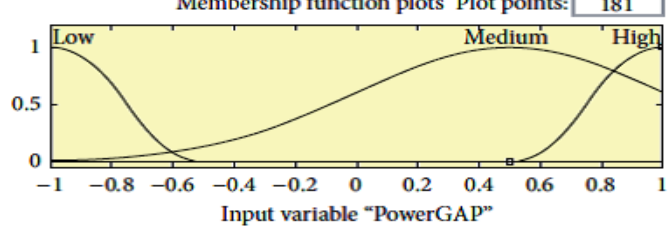

Fig. 7: Membership function of substation reserve capacity

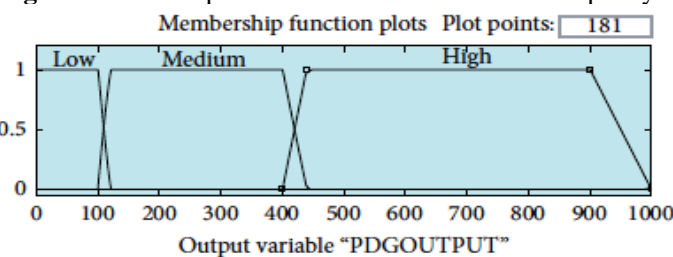

Fig. 9: Membership function of DG output Membership function plots Plot points

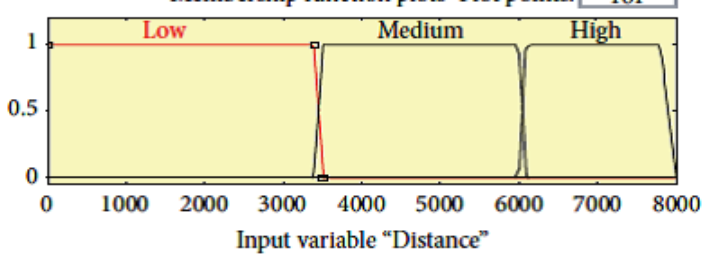

Fig. 11: Membership function of distance

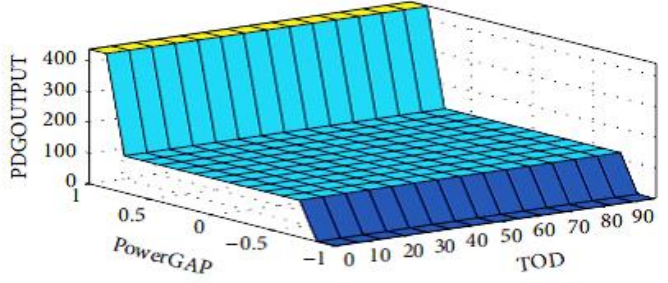

Fig. 13: Surface view of madami fuzzy model rules 


\section{Results and discussions}

To study the impact of distributed generation integration on stochastic voltage stability margin for a modified IEEE 37 feeder is utilized. For an unbalance load flow computation $2.5 \mathrm{KV}$ voltage and 2.5 MVA are chosen as base quantity. This study considers four different cases to know the impact of DG operational mode on stochastic voltage stability margin. The base case results are taken as benchmark to make comparative analysis for results obtained with fuzzy system based DG unit's integration.

\section{Base case}

The worst stochastic voltage stability margin computed without any DG integration for a whole day. It is to note that in this case phase A is always highly insecure from operation point of view and need immediate measures to improve voltage stability margin. All phases of substation node are always have negative voltage stability margin and concluded that additional energy sources is required to improved voltage security of test feeder.

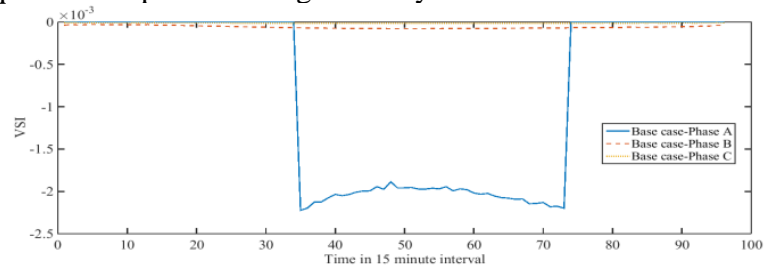

Fig. 15: Base case worst voltage stability margin

\section{PQ DG case}

In this scenario, three operational power factor of DG unit named as unity, 0.95 lag and 0.95 lead has considered. The impacts of DG operation on worst voltage stability margin are detailed as follows.

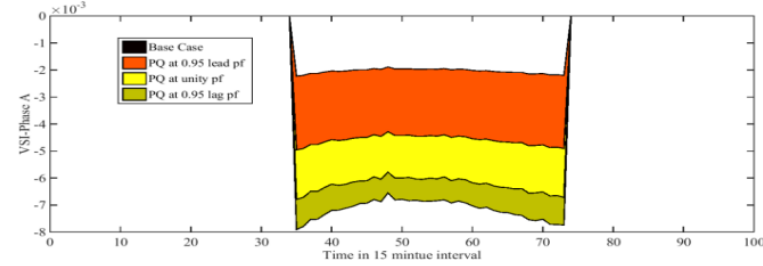

Fig. 16: PQ DG impact on worst voltage stability margin phase A

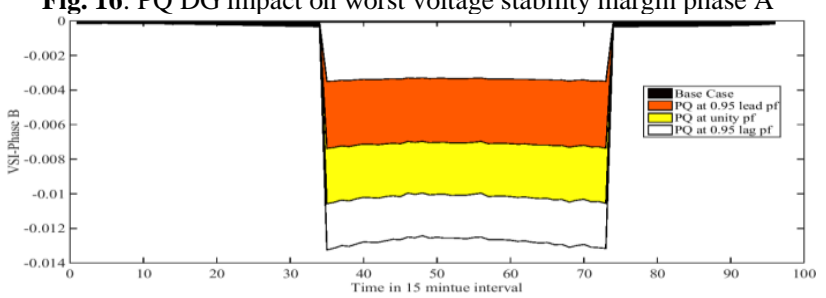

Fig. 17: PQ DG impact on worst voltage stability margin phase B

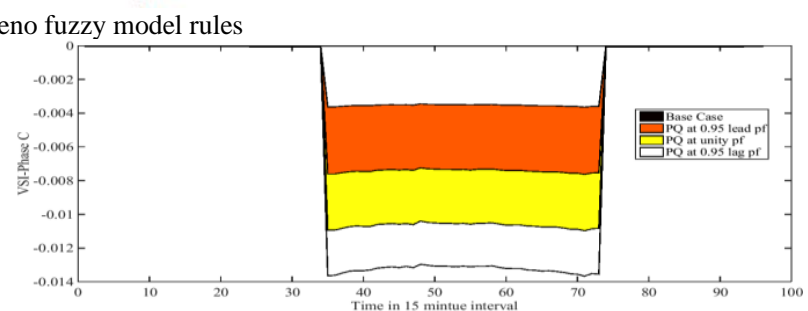

Fig. 18: PQ DG impact on worst voltage stability margin phase $\mathrm{C}$

From figure 16, 17 and 18, it is watched that PQ DG case enhanced the worst voltage stability as compared to the base case. PQ DG case at 0.95 lead p.f has demonstrated maximum voltage stability margin for all phases, the PQ DG model with unity p.f., got the second maximum voltage stability and the PQ DG case with 0.95 lag p.f., the next.

\section{PV DG case}

A constant voltage at node 734 is maintained with a tolerance of 4 $\times 10^{-3}$ per unit and the reactive power demand varied from 20 and 2500 KVAR, respectively.

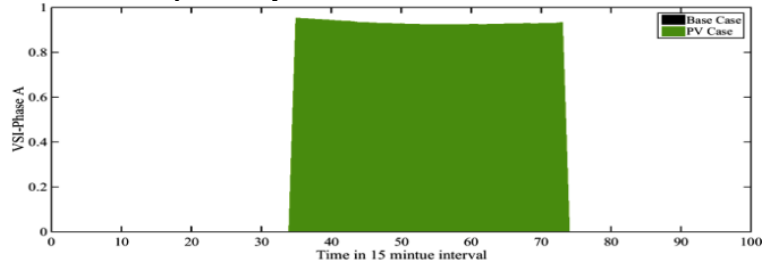

Fig. 19: PV DG impact on worst voltage stability margin phase A

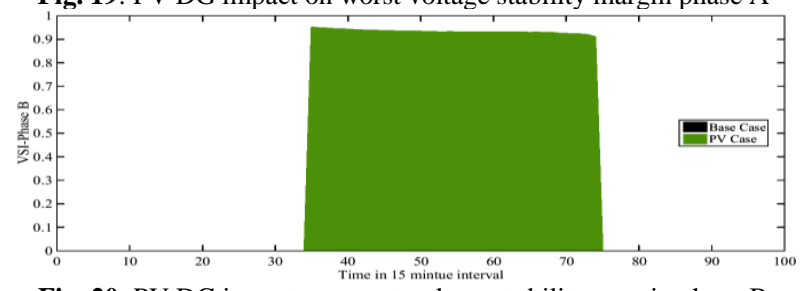

Fig. 20: PV DG impact on worst voltage stability margin phase B

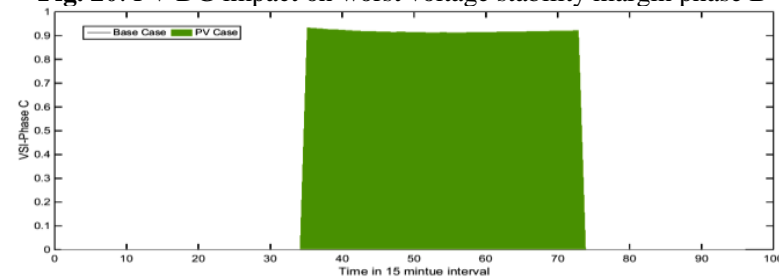

Fig. 21: PV DG impact on worst voltage stability margin phase $C$ In this scenario, $220 \mathrm{KW}$ capacities for PQ DG unit at 0.95 lead p.f., and $220 \mathrm{KW}$ capacities for PV DG unit are taken up for investigation. It is noted that PV DG unit turned all most exceedingly awful voltage stability margin of all phases into voltage secure nodes. Henceforth, it might reason that a mix of PQ and PV DG display are expected to enhance voltage security of test feeder.

\section{Combined PQ and PV case}

In this case to keep constant voltage at point of coupling, the reactive power demand varied from 996.6043 to $2500 \mathrm{KVAR}$. 


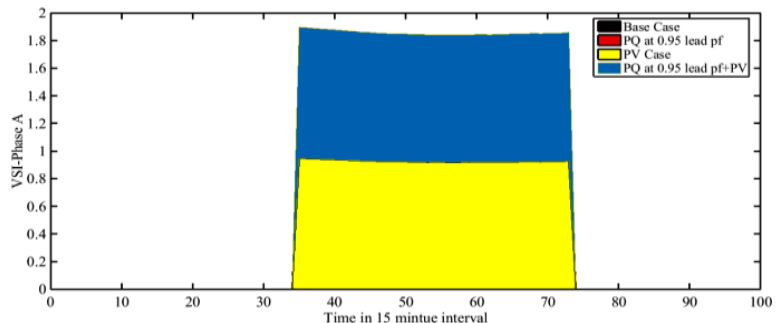

Fig. 22: Impact of PQ and PV DG on worst voltage stability margin phase A

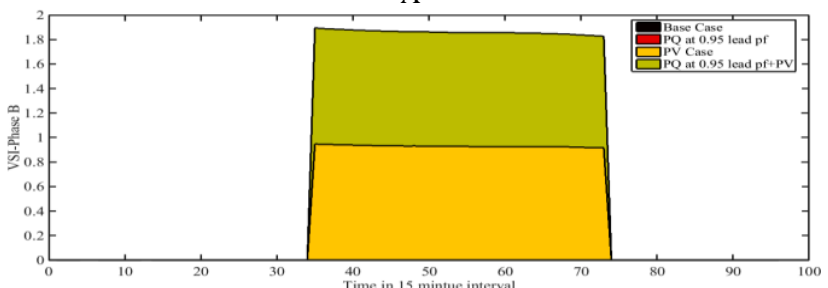

Fig. 23: Impact of PQ and PV DG on worst voltage stability margin phase B

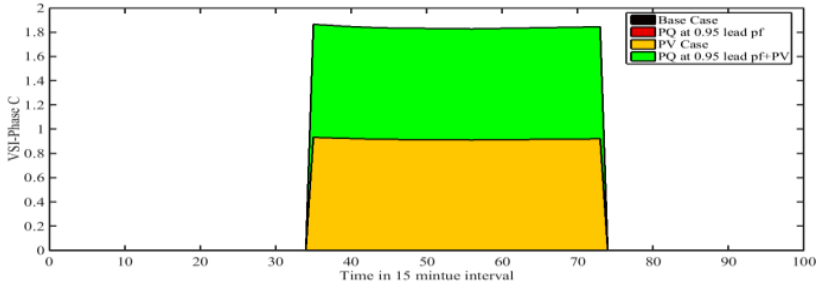

Fig. 24: Impact of PQ and PV DG on worst voltage stability margin phase $\mathrm{C}$

As appeared in figure 22,23 and 24 combined PQ and PV DG model has turned out all worst voltage stability margin nodes of all phases into voltage secure nodes significantly. Therefore combined PQ and PV model are much appropriate to test feeder secure operation and PV DG operation is much imperative than PQ at 0.95 lead p.f. case.

\section{Conclusion}

This paper has investigated the stochastic voltage stability margin for highly unbalance IEEE 37 node test feeder under three different DG operational scenarios and compared with results acquired in the base case. It is observed that voltage stability margin is found better combined PQ and PV DG case among other case. The PV DG operation stood on second position. This investigation will help for the better operation and better management of reactive power compensating devices. In addition, a fuzzy expert system is utilized for DG system integration and unbalance nature of distribution feeder is also discussed. Moreover, PV node handling capability of load flow proposed for practical feeder with good convergence.

\section{References}

[1] Haque MH, "A Fast Method for Determining the Voltage Stability Limit of a Power System", Electric Power Systems Research, Vol.32, No.1, (1995), pp.35-45, 1995.

[2] Sauer PW \& Pai MA, "Power system steady state stability and the load flow Jacobian", IEEE Trans. Power systems, Vol.5, No.4, (1990), pp.1374-1383.

[3] Nagaraju K, Sivanagaraju S, Ramana T \& Ganesh V, "A Novel Method to Evaluate Line Loadability for Distribution Systems with Realistic Loads", International Journal of Electrical and Computer Engineering, Vol.5, No. 12, (2011), pp.1824-29.

[4] Salama MM, Saied EM \& Abdel-Maksoud SM, "Steady state voltage instability assessment in a power system", Energy conversion and management, Vol.40, No.1, (1999), pp.59-69.

[5] Wang Y, Han X, Zhou X \& Zha H, "Line loadability analysis including var supply capability and load voltage characteristics", Third International Conference on Electric Utility Deregulation and Restructuring and Power Technologies, (2008), pp.1132-1136.
[6] Sharma JP \& Kamath HR, "Performance Analysis of Unbalance Radial Feeder with Time Varying Composite Load", Journal of Power and Energy Engineering, Vol.3, No.5, (2015), pp.56-70.

[7] Sharma JP \& Kamath HR, "Stochastic Voltage Assessment of Unbalance Radial Feeder", Journal of Electrical Systems, Vol.11, No.3, (2015), pp.258-270.

[8] Khushalani S, Solanki JM \& Schulz NN, "Development of threephase unbalanced power flow using PV and PQ models for distributed generation and study of the impact of DG models", IEEE Transactions on Power Systems, Vol.22, No.3, (2007), pp.1019-1025.

[9] Banerjee S, Chattopadhyay TK \& Chanda CK, "Voltage stability margin of distribution networks for composite loads", Annual IEEE India Conferenc, (2012), pp.582-587.

[10] Heslop S, MacGill I, Fletcher J \& Lewis S, "Method for determining a PV generation limit on low voltage feeders for evenly distributed PV and Load", Energy Procedia, Vol.57, (2014), pp.207-216.

[11] Sharma JP \& Kamath HR, "Fuzzy Logic Controller Based Distributed Generation Integration Strategy for Stochastic Performance Improvement", Advances in Electrical Engineering, (2016), pp.1-13.

[12] Moger T \& Dhadbanjan T, "Fuzzy logic approach for reactive power coordination in grid connected wind farms to improve steady state voltage stability", IET Renewable Power Generation, Vol.11, No.2, (2017), pp.351-361.

[13] Xu J, Ren C, Qin W, Han X \& Wang P, "Voltage stability analysis based on adaptive fuzzy logic considering load fluctuation", IEEE International Conference on Power System Technology, (2016), pp. $1-5$.

[14] Angelim JH \& Affonso CM, "Impact of distributed generation technology and location on power system voltage stability", IEEE Latin America Transactions, Vol.14, No.4, (2016), pp.1758-1765.

[15] Mehta P, Bhatt P \& Pandya V, "Optimal selection of distributed generating units and its placement for voltage stability enhancement and energy loss minimization", Ain Shams Engineering Journal, (2015).

[16] Abdelkhalek Azzouz M, Farag HE \& El-Saadany EF, "Real-Time Fuzzy Voltage Regulation for Distribution Networks Incorporating High Penetration of Renewable Sources”, IEEE Systems Journal, Vol.11, No.3, (2017), pp.1702-1711.

[17] Qamar H, Qamar H \& Vaccaro A, "Design of fuzzy logic controllers for decentralized voltage regulation in grid connected photovoltaic systems", IEEE International Conference on Fuzzy Systems, (2017), pp. 1-6.

[18] Moussa A, El-Gammal M, Abdallah EN \& Attia AI, "A genetic based algorithm for loss reduction in distribution systems", Alexandria Engineering Journal, Vol.43, No.6, (2004), pp.729735 .

[19] Alam MJE, Muttaqi KM, Sutanto D, Elder L \& A Baitch, "Performance Analysis of Distribution Networks under High Penetration of Solar PV", 21, rue d'Artois, F-75008 PARIS C6-103 CIGRE, (2012).

[20] Yammani C, Maheswarapu S \& Matam S, "Optimal placement of multi DGs in distribution system with considering the DG bus available limits", Energy and Power, Vol.2, No.1, (2012), pp.1823

[21] Tafreshi SM \& Mashhour E, "Distributed generation modeling for power flow studies and a three-phase unbalanced power flow solution for radial distribution systems considering distributed generation", Electric Power Systems Research,vol.79,no.4, (2009), pp.680-686.

[22] Geibel D, Arnold G \& Martini D, "Confirmation of extended electrical properties of PV inverters according to German MV-Grid code-Experiences in the certification process", $21^{\text {st }}$ International Conference on Electricity Distribution, (2011), pp.1-4.

[23] Sharma JP \& Kamath HR, "A Framework for Stochastic Performance Improvement of an Unbalance Radial Feeder", $P h D$ dissertation [Submitted], Mewar University, Chittorgarh, India, (2016) 